\title{
Analysis on the Travel Characteristics of Sharing Bikes Connected with Different Types of Public Transportation Stations
}

\author{
Xiaohua YU1, Xiaohui WANG, Yanna ZHAO \\ Jinan Rail Transit Group Co., Jinan, Shandong 250100, China
}

\begin{abstract}
In order to better solve the problem of unbalanced supply and demand of connected shared bikes, this paper takes shared bikes as the research object, analyzes the usage characteristics of connected bikes in different types of public transport stations, and puts forward a data-based feature extraction method of shared bikes. Firstly, the usage data of shared bikes were collected, and the starting and finishing points were decoded. The public transport stations were divided into five typical types according to the decoded longitude, latitude and surrounding land types. Secondly, the connectivity activity, connectivity distance and user loyalty are put forward as the characteristic indicators of bike-sharing travel. Finally, taking the bicycle data of Chaoyang District of Beijing as an example, the travel characteristic indexes of shared bikes are analyzed. The results show that, as the "last kilometer" travel connecting tool of public transport, the peak of the use of shared bikes connecting residential stations is 6:30 to $9: 30$, and that of other stations is 7:30 to 9:30. The connecting distance of shared bikes is generally less than $2 \mathrm{~km}$, but the connecting distance of office sites can reach $3 \mathrm{~km}$, and this site has the highest user loyalty.
\end{abstract}

Keywords: Sharing bikes, public transportation stations, travel characteristics

\section{Introduction}

Relying on the advantages of wide distribution, flexibility and convenience, shared bikes meet the needs of passengers to travel in short distances and connect to public transportation, providing a new idea to solve the "last kilometer" problem, but at the same time, there are also problems such as random parking, unreasonable distribution and low utilization rate. Therefore, the analysis of the travel characteristics of shared bikes not only helps operators to understand the use characteristics of the bikes, but also lays a foundation for accurate demand prediction and scheduling of shared bikes in the later stage, which is conducive to improving the utilization rate of shared bikes.

In the existing studies, some scholars study the use data of shared bikes and analyze the travel characteristics of shared bikes connected to urban tracks and their role in the connection of urban tracks. Some foreign researchers [1-3] and others studied the factors affecting the use of shared bikes mainly from the aspects of users, environment, technology and so on, and the results revealed the great potential of developing the combined travel of rail transit and shared bikes. Zhou Rong, Yin Qiuyi,

${ }^{1}$ Corresponding author: Xiaohua Yu, Jinan Rail Transit Group Co., Jinan, Shandong 250100, China; Email:18532327@qq.com. 
Bai Yunyun et al. [4-6] analyzed the distribution, travel peak periods and cycling length of shared bikes around the subway. The research on cycling length was mostly based on questionnaire survey. Cheng Yuan [7]conducted a previous study and analyzed at the level of which station, indicating that shared bikes have a greater impact on residential and commercial areas. Some scholars focus on the study of models, including the demand prediction model of connected shared bikes and the scheduling model of shared bikes [8]. Qunchen [9] consider the bike rental behavior of each user, analyze the user's bike rental behavior, construct the dynamic evolution process of bike borrowing and return, and establish a mathematical model to determine the configuration of the bike fleet at each station when the bike is repositioned in the bike-sharing system.

Most of the existing studies focus on the travel characteristics of shared bikes, and there are few studies on the connection of shared bikes. The use characteristics of connected shared bikes are closely related to the surrounding properties and station types, but the research on this aspect is still insufficient. This study combines the characteristics of shared bikes with the types of public transport stations, making the configuration of shared bikes more refined, which is conducive to the maintenance of the sites in the later stage and of great significance for improving the utilization rate of shared bikesat public transport stations.

\section{Data Preparation and Analysis Method}

\subsection{Basic Data Preparation and Processing}

Bike-sharing began to rise until 2016, when it entered a stage of rapid development. 2017 became a significant year with the fastest growth rate of its user scale. Due to the increasingly prominent operation and management problems in the later period, the operating environment has changed, and the use of shared bikes has gradually gone to "decline".2017 is the year of the fastest development of bike-sharing. The use data of bike-sharing is made public on the Internet, which can highlight the travel characteristics of most users, so it is very representative. Through data screening and statistics, basic data of shared bikes are obtained, such as number of stations, number of bikes. In order to study the travel characteristics of bike-sharing connected to different types of public transport stations, the basic data of this study adopted the bike-riding data of Chaoyang District, Beijing from May 10, 2017 to May 16, 2017 (Table 1). Due to the high site coverage rate, this paper takes several representative sites with high loan and return volume in Chaoyang District as examples to analyze and classify their land use properties. Firstly, the data shall be screened initially according to the requirements:

(1) The data with obvious errors (such as data missing, incomplete, etc.) shall be deleted.

(2) The lock threshold of bike-sharing switch is 1 minute. The data with the same USERID and two consecutive Start Time intervals of less than 1 minute are combined as one data. 
Table 1. Data processing of Mobike.

\begin{tabular}{ccccccc}
\hline $\begin{array}{c}\text { Order } \\
\text { ID }\end{array}$ & $\begin{array}{c}\text { User } \\
\text { ID }\end{array}$ & $\begin{array}{c}\text { Bike } \\
\text { ID }\end{array}$ & $\begin{array}{c}\text { Bike } \\
\text { Type }\end{array}$ & $\begin{array}{c}\text { Start } \\
\text { Time }\end{array}$ & $\begin{array}{c}\text { Borrow Point } \\
\text { Location }\end{array}$ & $\begin{array}{c}\text { Return Point } \\
\text { Location }\end{array}$ \\
\hline 163020 & 378959 & 22541 & 1 & $5 / 100: 00$ & wx4f5pf & wx4f5pe \\
3428602 & 140756 & 354271 & 1 & $5 / 100: 00$ & wx4g20b & wx4erbf \\
4580017 & 693933 & 459074 & 1 & $5 / 100: 00$ & wx4ersk & wx4ersf \\
4117589 & 482046 & 420604 & 1 & $5 / 100: 00$ & wx4dnv2 & wx4dphv \\
2851526 & 895961 & 300008 & 2 & $5 / 100: 00$ & wx4ff3z & wx4ff90 \\
\hline
\end{tabular}

After preliminary data screening, the Geohash of the existing data is decoded into latitude and longitude by Python programming, and the result is shown in Table 2.

Table 2. Geohash decoded partial data.

\begin{tabular}{|c|c|c|c|c|c|c|c|c|}
\hline $\begin{array}{l}\text { Orde } \\
\mathrm{r} \text { ID }\end{array}$ & $\begin{array}{l}\text { Use } \\
\text { r ID }\end{array}$ & $\begin{array}{r}\text { Bik } \\
\text { e ID }\end{array}$ & $\begin{array}{c}\text { Borrow } \\
\text { Point }\end{array}$ & $\begin{array}{c}\text { Return } \\
\text { Point }\end{array}$ & \multicolumn{2}{|c|}{$\begin{array}{l}\text { Borrow the bike to } \\
\text { latitude and longitude }\end{array}$} & \multicolumn{2}{|c|}{$\begin{array}{l}\text { Return the bike to } \\
\text { latitude and longitude }\end{array}$} \\
\hline $\begin{array}{c}1630 \\
20\end{array}$ & $\begin{array}{l}378 \\
959\end{array}$ & $\begin{array}{c}225 \\
41\end{array}$ & wx4f5pf & wx4f5pe & $\begin{array}{c}39.769821 \\
17\end{array}$ & $\begin{array}{c}116.50245 \\
67\end{array}$ & $\begin{array}{c}39.76844 \\
788\end{array}$ & $\begin{array}{c}116.5038 \\
3\end{array}$ \\
\hline $\begin{array}{c}3428 \\
602\end{array}$ & $\begin{array}{l}140 \\
756\end{array}$ & $\begin{array}{l}354 \\
271\end{array}$ & $w \times 4 g 20 b$ & wx4erbf & $\begin{array}{c}39.951095 \\
58\end{array}$ & $\begin{array}{c}116.36787 \\
41\end{array}$ & $\begin{array}{l}39.95109 \\
558\end{array}$ & $\begin{array}{c}116.3596 \\
344\end{array}$ \\
\hline $\begin{array}{c}4580 \\
017\end{array}$ & $\begin{array}{l}693 \\
933\end{array}$ & $\begin{array}{l}459 \\
074\end{array}$ & wx4ersk & wx4ersf & $\begin{array}{c}39.970321 \\
66\end{array}$ & $\begin{array}{c}116.35139 \\
47\end{array}$ & $\begin{array}{c}39.97306 \\
824\end{array}$ & $\begin{array}{c}116.3486 \\
481\end{array}$ \\
\hline $\begin{array}{c}4117 \\
589\end{array}$ & $\begin{array}{l}482 \\
046\end{array}$ & $\begin{array}{l}420 \\
604\end{array}$ & wx4dnv2 & wx 4dphv & $\begin{array}{l}39.756088 \\
26\end{array}$ & $\begin{array}{c}116.31294 \\
25\end{array}$ & $\begin{array}{c}39.75334 \\
167\end{array}$ & $\begin{array}{c}116.3307 \\
953\end{array}$ \\
\hline $\begin{array}{c}2851 \\
526\end{array}$ & $\begin{array}{l}895 \\
961\end{array}$ & $\begin{array}{l}300 \\
008\end{array}$ & wx4ff3z & wx4ff90 & $\begin{array}{c}39.868698 \\
12\end{array}$ & $\begin{array}{c}116.47636 \\
41\end{array}$ & $\begin{array}{c}39.86457 \\
825\end{array}$ & $\begin{array}{c}116.4777 \\
374\end{array}$ \\
\hline
\end{tabular}

In order to ensure that the research data are within the boundary of Beijing, the geographic coordinates (39 "26" to 41 " 03 " north latitude, 115 "25" to 117 "30" east longitude) beyond the boundary of Beijing are deleted. For latitude and longitude, when accurate to 7 decimal places, the accuracy is $1 \mathrm{~cm}$. Therefore, latitude and longitude only need to be reserved to 7 decimal places.

\subsection{Classification of Public Transport Stations Based on Land Use Types}

There is an interactive relationship between transportation and land use. Different land uses around public transport stations have different degrees of attraction to passenger flow, and the use of surrounding connected shared bikes is also different. According to "urban land classification and planning construction land standards", land use is generally divided into commercial land, residential land, comprehensive land, industrial land and other land. According to the location of the public transport stations, the public transport stations are divided into commercial stations, residential stations, office stations, hub stations and school stations.

Python tools were used to output the public transport stations connected to shared bikes with more than 150 times per day, which are 13 stations, and the land use of their geographical locations were analyzed and classified according to the types of stations as shown in Table 3. 
Table 3. Location and types of bike docking stations in Chaoyang District.

\begin{tabular}{|c|c|c|c|c|c|c|}
\hline $\begin{array}{c}\text { Serial } \\
\text { Number }\end{array}$ & $\begin{array}{l}\text { Connect to } \\
\text { the rental }\end{array}$ & Longitude & Latitude & $\begin{array}{c}\text { Public } \\
\text { Transport }\end{array}$ & $\begin{array}{c}\text { Geographical } \\
\text { Position }\end{array}$ & Site type \\
\hline 1 & wx $4 \mathrm{~g} 4 \mathrm{ch}$ & 116.4942169 & 39.9085235 & $\begin{array}{l}\text { Subway } \\
\text { station }\end{array}$ & $\begin{array}{l}\text { West exit of } \\
\text { Beijing East }\end{array}$ & Hub \\
\hline 2 & $\mathrm{wx} 4 \mathrm{~g} 4 \mathrm{cj}$ & 116.4955902 & 39.9085235 & $\begin{array}{l}\text { Subway } \\
\text { station }\end{array}$ & $\begin{array}{c}\text { East entrance of } \\
\text { Beijing East }\end{array}$ & Hub \\
\hline 3 & $\mathrm{wx} 4 \mathrm{~g} 4 \mathrm{e} 9$ & 116.4791107 & 39.9222564 & $\begin{array}{c}\text { Bus } \\
\text { station }\end{array}$ & $\begin{array}{c}\text { Beijing First } \\
\text { Integrated Chinese }\end{array}$ & Business \\
\hline 4 & wx4g53h & 116.5161895 & 39.9085235 & $\begin{array}{c}\text { Bus } \\
\text { station. }\end{array}$ & $\begin{array}{c}\text { Quintessence } \\
\text { Garden Art Trading }\end{array}$ & Office \\
\hline 5 & wx4g559 & 116.5010833 & 39.9222564 & $\begin{array}{l}\text { Subway } \\
\text { station }\end{array}$ & Suning Life Square & Business \\
\hline 6 & $w x 4 g 55 f$ & 116.5024566 & 39.9236297 & $\begin{array}{r}\text { Bus } \\
\text { station }\end{array}$ & $\begin{array}{l}\text { Near Building 33, } \\
\text { Balizhuang Dongli }\end{array}$ & Residence \\
\hline 7 & $w \times 4 g 57 t$ & 116.5175628 & 39.9222564 & $\begin{array}{c}\text { Bus } \\
\text { station }\end{array}$ & $\begin{array}{l}\text { Near Building 33, } \\
\text { Gandew Garden }\end{array}$ & Residence \\
\hline 8 & $w \times 4 g 57 v$ & 116.5175628 & 39.9236297 & $\begin{array}{c}\text { Bus } \\
\text { station }\end{array}$ & $\begin{array}{l}\text { Near Building 12, } \\
\text { Gandew Garden }\end{array}$ & Residence \\
\hline 9 & wx $4 g 57 y$ & 116.5189361 & 39.9236297 & $\begin{array}{c}\text { Bus } \\
\text { station }\end{array}$ & $\begin{array}{l}\text { Near Building 2, } \\
\text { Gandew Garden }\end{array}$ & Residence \\
\hline 10 & wx4g59n & 116.5299224 & 39.9085235 & $\begin{array}{c}\text { Bus } \\
\text { station }\end{array}$ & $\begin{array}{l}\text { Near Block A, } \\
\text { No.5, Tangjia }\end{array}$ & Residence \\
\hline 11 & wx4gh30 & 116.5546417 & 39.9085235 & $\begin{array}{c}\text { Bus } \\
\text { station、 }\end{array}$ & $\begin{array}{l}\text { Jinxin Business } \\
\text { Building }\end{array}$ & Office \\
\hline 12 & wx4gh7y & 116.5628814 & 39.9236297 & $\begin{array}{c}\text { Bus } \\
\text { station }\end{array}$ & $\begin{array}{c}\text { Beijing } \\
\text { Broadcasting }\end{array}$ & School \\
\hline 13 & wx $4 \mathrm{ghc} 2$ & 116.5766143 & 39.9098968 & $\begin{array}{c}\text { Bus } \\
\text { station }\end{array}$ & $\begin{array}{c}\text { Xiliuxiang Village, } \\
\text { Beijing East }\end{array}$ & Residence \\
\hline
\end{tabular}

\subsection{Riding Distance Analysis Based on AutoNavi API}

In actual road conditions, due to network constraints, different modes of transportation and different travel distances are adopted between the same starting and finishing points. The AutoNavi API path planning technology can put the start and end points on the map, and obtain the true cycling distance according to the road conditions. Compared with the existing Pythagorean Theorem and spherical triangle method, the result is accurate.

The application of AutoNavi API technology to calculate the cycling distance requires three steps: the first step is to apply for the "Web Service API" Key (Key); The second step is to concatenate the HTTP request URL and send the Key of the application together as the required parameter. The third step is to receive the data returned by the HTTP request (in either JSON or XML format) and parse the data.

\section{The Characteristic of ConnectedShared Bike}

\subsection{Trip Characteristic Parameters}

The travel characteristics of connected shared bikes should reflect the frequency and efficiency of the use of the bikes as well as users' habit of using the bikes. Therefore, the connectivity activity, connectivity distance and user loyalty indexes are selected as the travel parameters of shared bikes. 
Connection activity refers to the number of shared bikes borrowed and returned for connection near a public transport station in a unit time, reflecting the frequency of use of shared bikes. The more shared bikes are borrowed for connection, the more active the site will be.

The connecting distance refers to the shortest distance from the start to the end of the Gaode map specified by users when connecting with shared bikes. The offset route between the start and end points is ignored. The riding distance method based on the Gaode map API is adopted for calculation.

User loyalty refers to the proportion of users with the frequency $>1$ connected by shared bikes on the same site in the total number of users on the site within a unit time. The higher the user loyalty, the more fixed the bike-sharing users are.

\subsection{Analysis of Mobike Trip Characteristics in Beijing}

\subsubsection{Connection Activity Analysis}

According to different statistical periods, the connection activity can be divided into two types: daily connection activity and hourly connection activity.

(1) Daily connection activity

Daily connection activity refers to the number of shared bikes borrowed and returned at the same site on a daily basis within a week. After a week of data analysis, the results are shown in Figure 1.

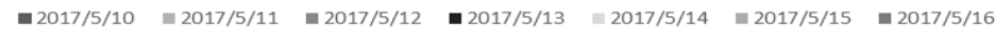

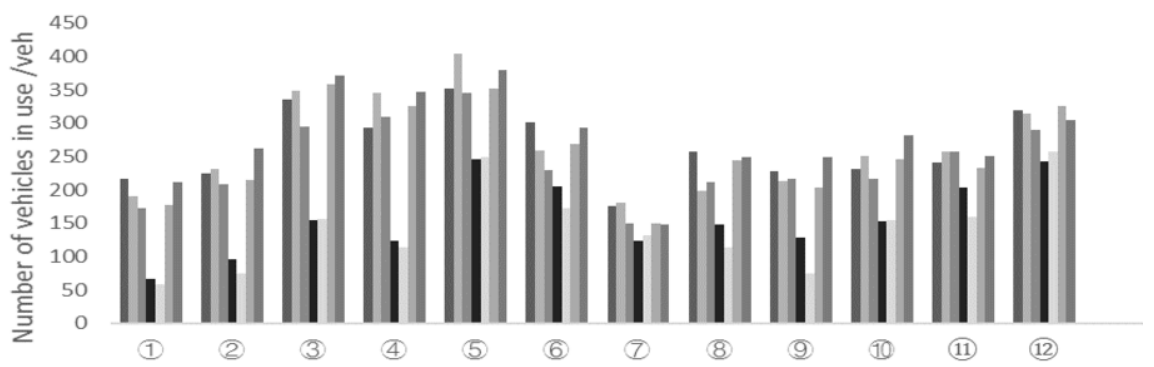

\footnotetext{
(1) West exit of Beijing East Railway Station (2) East entrance of Beijing East Railway Station (3) Beijing First Integrated Chinese and Western Hospital (4) Quintessence Garden Art Trading Center (5) Near Building 33, Balizhuang Dongli (6) Near Building 33, Gandew Garden (7) Near Building 12, Gandew Garden (8) Near Building 2, Gandew Garden 9 Near Block A, No.5, Tangjia Village 10 Suming Life Square (11)Beijing Broadcasting Institute(12)Xiliuxiang Village, Beijing East Railway Station
}

Figure 1. Daily connectivity activity of shared bikes at each site.

Figure 1 shows that in working days, the number of shared bikes in each site does not change significantly, which has little relationship with land use. However, the number of shared bikes in non-working days changes significantly compared with working days. The number of shared bikes used on non-weekdays was significantly lower than that on weekdays. There is no need to consider the time to travel outside work, and private cars are more comfortable to take public transportation, so most people will choose private cars to travel. Shared bikes are limited to the number of people who can take them at one time and the age of the users. Therefore, they are not 
suitable for those who take a family as a unit on non-working days, and the number of times of use will be significantly reduced.

(2) when the connection activity

Time connection activity refers to the number of shared bikes borrowed and returned at the site in an hour within a day. Select a day within a working week to draw the use of shuttle bikes at different types of stations within a day, and choose May 10 as the research object for analysis, as shown in Figure 2.

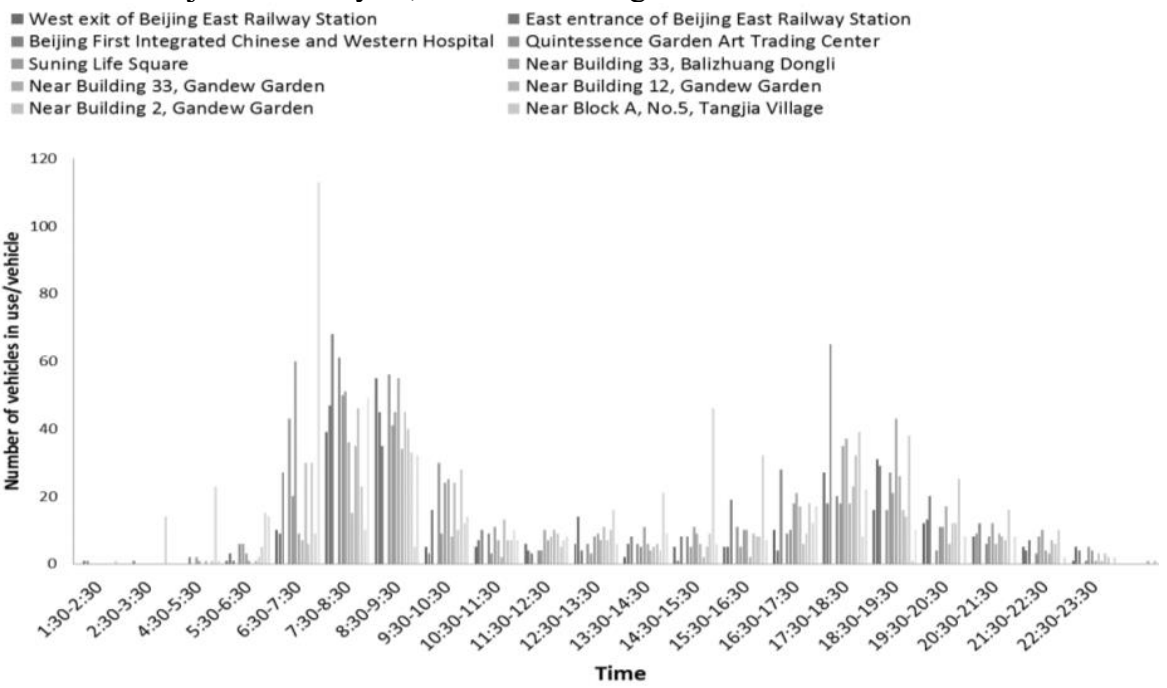

Figure 2. Connectivity of bike-sharing at each site.

For the 13 stations studied, there is a period of the highest connectivity activity in the morning and evening, which is basically consistent with the morning and evening peak hours, as shown in Figure 2. Due to the impact of housing prices in Beijing, most office workers live outside the city. Therefore, for residential sites, the connectivity activity ranges from 6:30 to 9:30 in the morning peak hours, while for other types of sites, the connectivity activity ranges from 7:30 to 9:30 in the morning peak hours. It shows that the morning rush hour of residential sites is earlier and lasts for a long time, which is consistent with the actual situation.

\subsubsection{Connection Distance Analysis}

The connecting distance of shared bikes refers to the size of the influence domain of the connecting stations, namely the distance from the bike rental point of the starting place to the public transport station or from the public transport station to the destination bike rental point, reflecting the use efficiency of the bikes. The connection distance distribution is shown in Figure 3. Among all types of stations, the connection distance of more than $81.4 \%$ of single users is short distance travel, generally within $2000 \mathrm{~m}$. Due to the limitation of working time, about $17 \%$ of users in office stations ride a long distance, up to $3000 \mathrm{~m}$.For hub stations, $8 \%$ will choose to ride a longer distance, reaching $3500 \mathrm{~m}$. The number of cyclists over $4000 \mathrm{~m}$ is almost zero. 


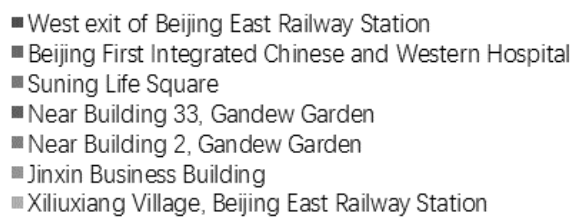

- East entrance of Beijing East Railway Station

- Quintessence Garden Art Trading Center

- Near Building 33, Balizhuang Dongli

- Near Building 12, Gandew Garden

- Near Block A, No.5, Tangjia Village

* Beijing Broadcasting Institute

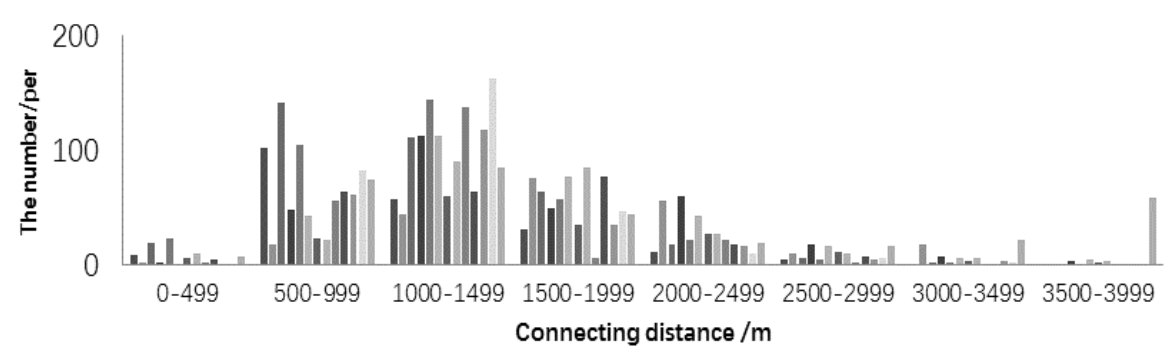

Figure 3. Schematic diagram of the distance between different types of stations.

\subsubsection{User Loyalty Index}

User loyalty reflects users' habit of using bicycles. In the data of the use of a bike, the USERID represents the unique code of the user, and the ID code of each user is fixed. The more times the same user connects to the shared bike at the same site, the higher the user's loyalty to the shared bike. From May 10 to May 16, 2017, the user loyalty of each type of site was analyzed, and the results were shown in Table 4.

In Table 4, office sites account for the highest proportion, followed by residential sites. Because most users of office sites are office workers, the time before work is tight. The speed of shared bikes is faster than that of walking, and there is no congestion in the process of driving. Therefore, most office workers are loyal to connect public transportation to office areas with shared bikes, and users of office sites have the highest loyalty. The main service object of residential site is residents, and the service group is limited, so the user loyalty is high. The school site is similar to the residential site in that its main service objects are students. However, because of the influence of schoolwork, students' spontaneity of travel is lower than that of residents, and their user loyalty is lower than that of residential sites. Commercial sites and hub sites serve the public, with large traffic and the lowest user loyalty.

Within a week, more than $50 \%$ of the people in office sites and residential sites use the same site more than one time, and nearly $50 \%$ of the people in school sites travel more than one time, indicating relatively high user loyalty. Hub sites have the lowest user loyalty, about $31.6 \%$. Each site service group is different, has the great influence to the user loyalty. User loyalty requirements for the minimum amount of shared bikes should meet the needs of loyal users, and put forward requirements for the amount of shared bikes. At the same time, user loyalty can become an important index for operators to evaluate the fixed income of the site. 
Table 4. User loyalty of different types of sites.

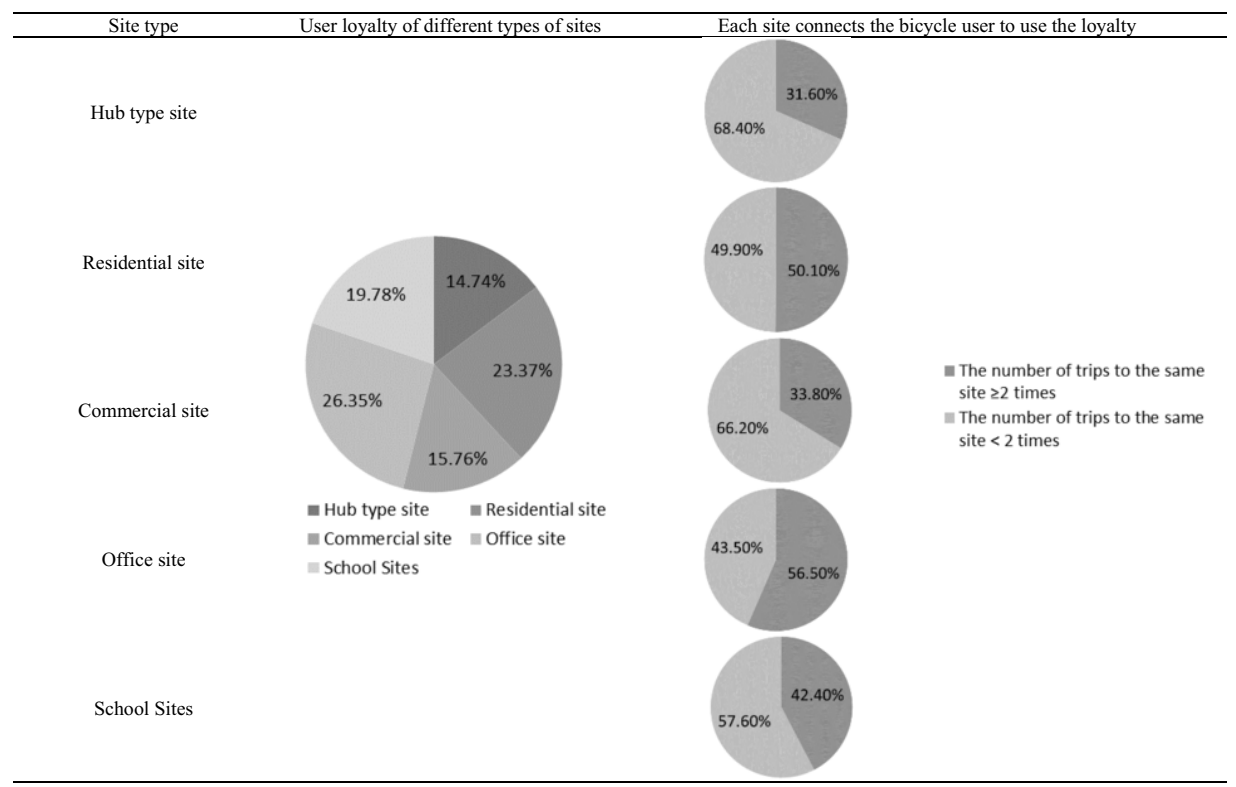

\subsection{Suggest}

Better connection planning based on the use characteristics of shared bikes can increase the number of shared bikes and promote the development of shared bikes. Based on the above analysis, the following suggestions are put forward:

(1) The analysis of connection activity shows that the morning rush hour of residential stations starts earlier and lasts longer than other stations. Therefore, operators can prioritize the scheduling of residential stations in the morning rush hour and reasonably arrange the priority of the scheduling order of shared bikes, so as to make the configuration of shared bikes more detailed.

(2) The cycling distance analysis of the shuttle bike shows that users mostly travel within $2 \mathrm{~km}$ for a short distance. Therefore, the government should improve the network of public transportation lines, increase the coverage rate of bus stops, strengthen the publicity of "B+R", and make shared bikes play a bigger role, so as to relieve traffic congestion.

(3) The analysis results of user loyalty characteristics show that user loyalty is related to the stability of surrounding population. Residential and office sites have the highest population stability, so user loyalty is high. Operators should improve the comfort and cheapness of shared bikes, increase travelers' willingness to choose shared 
bikes, and enhance users' loyalty to shared bikes, so as to make more travelers choose shared bikes.

\section{Conclusion}

Shared bikes have been accepted by the public with the advantages of "on-demand, ondemand and on-demand", and play an important role in connecting public transportation. This paper analyzes the decoded data of shared bikes from three perspectives, namely, the connection activity, the connection distance and the user loyalty. It concludes that (1) there are still morning peak and evening peak when connected to shared bikes during working days, and the morning peak is more obvious;(2) Commuters are more inclined to ride for medium and long distances;(3) Different types of sites have different user loyalty, which is not only helpful for operators to understand the usage characteristics of bicycle users, but also of great significance to the research of scheduling time and scheduling quantity in the later period.

\section{References}

[1] Sebastian M, Miguel RM, Francisco LC. User characteristics influencing use of a bicycle-sharing system integrated into an intermodal transport network in Spain.International Journal of Sustainable Transportation. $2020 \mathrm{Jul}$;14(7):513-24.

[2] Gonzalez F, Melo-Riquelme C, Grange LD. A combined destination and route choice model for a bicycle sharing system, Transportation.2016 May;43(3): 407-23.

[3] Barna B, Zombor B, Péter I, Enikő ZV. Does Uber affect bicycle-sharing usage? Evidence from a natural experiment in Budapest. Transportation Research Part A. 2020 Jan; 133:290-320.

[4] Zhou R, Wang YQ, Zhu L, Ji SJ. Research on travel characteristics of shared bikes based on temporal and spatial data. Journal of Wuhan University of Technology. 2019 Feb;43(01):159-63.

[5] Yin QY, Zhen F, Luo SSX, Yan X, Guo SP. Influencing factors and layout suggestions of public bicycle travel space in new city. Urban Research. 2018 Dec; 12:9-15+46.

[6] Chen QF, Fu ZY. Research on spatial-temporal characteristics of residents' cycling behavior under the influence of bike-sharing: A case study of central urban area of Nanjing. Urban Planning Society of China. 2018 Nov; 9:853-61.

[7] Cheng Y, Xian K, Xu XY. Research on traffic distribution and users' cycling characteristics of shared bikes in Beijing. Institute of Urban Transportation. 2018 Oct; 10:810-19.

[8] Nadav L, Chen G, Eran BE. An exploratory study of spatial patterns of cycling in Tel Aviv using passively generated bike-sharing data. Journal of Transport Geography. 2019 Apr; 76:325-34.

[9] Chen Q, Liu M, Liu XY. Bike fleet allocation models for repositioning in bike-sharing systems. IEEE Intelligent Transportation Systems Magazine.2018 Jan;10(1): 19-29. 